\title{
Experimental Study on LTCC Glass-Ceramic Based Dual Segment Cylindrical Dielectric Resonator Antenna
}

\author{
Ravi Kumar Gangwar, ${ }^{1}$ S. P. Singh, ${ }^{2}$ Meenakshi Choudhary, ${ }^{3}$ D. Kumar, ${ }^{3}$ \\ G. Lakshmi Narayana Rao, ${ }^{4}$ and K. C. James Raju ${ }^{4}$ \\ ${ }^{1}$ Department of Electronics Engineering, Indian School of Mines, Dhanbad 826004, India \\ ${ }^{2}$ Department of Electronics Engineering, Indian Institute of Technology, Banaras Hindu University, Varanasi 221005, India \\ ${ }^{3}$ Department of Ceramic Engineering, Indian Institute of Technology, Banaras Hindu University, Varanasi 221005, India \\ ${ }^{4}$ School of Physics, University of Hyderabad, Hyderabad 500 046, India
}

Correspondence should be addressed to Ravi Kumar Gangwar; ravi8331@gmail.com

Received 21 November 2012; Accepted 10 February 2013

Academic Editor: Baolin Wang

Copyright ( 2013 Ravi Kumar Gangwar et al. This is an open access article distributed under the Creative Commons Attribution License, which permits unrestricted use, distribution, and reproduction in any medium, provided the original work is properly cited.

The measured characteristics in $\mathrm{C} / \mathrm{X}$ bands, including material properties of a dual segment cylindrical dielectric resonator antenna (CDRA) fabricated from glass-ceramic material based on $\mathrm{B}_{2} \mathrm{O}_{3}-\mathrm{La}_{2} \mathrm{O}_{3}-\mathrm{MgO}$ glass and $\mathrm{La}\left(\mathrm{Mg}_{0.5} \mathrm{Ti}_{0.5}\right) \mathrm{O}_{3}$ ceramic, are reported. The sintering characteristic of the ceramic in presence of glass is determined from contact angle measurement and DTA. The return loss and input impedance versus frequency characteristics and radiation patterns of CDRA at its resonant frequency of $6.31 \mathrm{GHz}$ are studied. The measured results for resonant frequency and return loss bandwidth of the CDRA are also compared with corresponding theoretical ones.

\section{Introduction}

Several investigators have focused attention on dielectric resonator antennas (DRAs) due to their simple geometry, small size, low cost, high radiation efficiency, flexible feed arrangement, wide range of material dielectric constants, ease of excitation, and easily controlled characteristics [1-5]. DRAs are available in various basic classical shapes such as rectangular, cylindrical, spherical, and hemispherical geometries. The techniques used for bandwidth enhancement of the DRAs include changing the aspect ratio of DRA, employing multisegments and stacked DRAs, and varying the dielectric constant of DRA material. DRAs having lower dielectric constant values are preferred for wideband applications. This results in weak coupling. Multisegment DRAs can be used to surmount this problem $[6,7]$.

Due to the incessantly increasing demands of miniaturizing the important passive microwave components, ceramic dielectrics are used as dielectric resonators and filters and antennas in many small microwave systems including wireless portable devices. However, microwave dielectric materials that possess high dielectric constant and quality factor usually need a very high sintering temperature and long soaking time to achieve enough density. There are three approaches to reducing the sintering temperature of the dielectric ceramics: (i) addition of low-melting glass [8] and sintering aids including carbonates and oxides [9], (ii) chemical processing [10], and (iii) smaller particle sizes for the starting materials [11]. Liquid-phase sintering with glass additives is the least expensive among them. However, if the amount of frits is large, the network formers contained in the remaining glass materials such as $\mathrm{B}_{2} \mathrm{O}_{3}$ and $\mathrm{SiO}_{2}$ can profoundly absorb the microwave power at high frequencies, degrading the quality factor of the final materials [12]. Compared to the Liquid-phase sintered ceramics with low-melting glass frits in which the glass phase remains, another approach of using low temperature cofired ceramics (LTCCs), "glassceramic" where glass frits crystallize during the sintering 
stage produces a better result. The advantages offered by this glass-ceramic approach include shape stability after sintering, improved dielectric properties, mechanical strength, and controlled thermal expansion. Therefore, low temperature cofired ceramics (LTCCs) have a great importance to the electronic industry for building smaller RF modules and for fulfilling the need to miniaturize the devices in the wireless communication industry [13]. La based complex perovskite ceramic $\mathrm{La}\left(\mathrm{Mg}_{0.5} \mathrm{Ti}_{0.5}\right) \mathrm{O}_{3}$ has negative temperature coefficient of resonant frequency $\left(\tau_{f}\right)$ and high $Q$ value. It exhibits dielectric constant around $25-28 ; Q \times f$ is $63100-73000 \mathrm{GHz}$ depending upon processing conditions. $\mathrm{La}\left(\mathrm{Mg}_{0.5} \mathrm{Ti}_{0.5}\right) \mathrm{O}_{3}$ ceramics have suitable microwave dielectric properties for the application of dielectric resonators, antenna, and filters [14, 15]. Sintering temperatures of these materials are high, that is, in the range of $1500^{\circ}-1600^{\circ} \mathrm{C}$. Lin et al. [16] prepared LTCC material with $\mathrm{La}\left(\mathrm{Mg}_{0.5} \mathrm{Ti}_{0.5}\right) \mathrm{O}_{3}$ ceramics and $\mathrm{B}_{2} \mathrm{O}_{3}-\mathrm{La}_{2} \mathrm{O}_{3}$ $\mathrm{MgO}$ glass and had shown that these LTCC glass-ceramics can be sintered at $850^{\circ} \mathrm{C}$ and had excellent microwave dielectric properties $\varepsilon_{r}=11.8, Q \times f=14700 \mathrm{GHz}$ and $\tau_{f}=$ $7.4 \mathrm{ppm}^{\circ} \mathrm{C}$.

In this paper, experimental investigation on a wideband dual segment cylindrical dielectric resonator antenna (CDRA) fabricated from glass-ceramic materials based on $\mathrm{B}_{2} \mathrm{O}_{3}-\mathrm{La}_{2} \mathrm{O}_{3}-\mathrm{MgO}$ (BLM) glass with $\mathrm{La}\left(\mathrm{Mg}_{0.5} \mathrm{Ti}_{0.5}\right) \mathrm{O}_{3}$ (LMT) ceramic along with its material properties is carried out. The crystallization behavior of BLM glass is investigated by differential thermal analysis (DTA). The sintering characteristic of the ceramic in presence of glass was determined from contact angle measurement. The dielectric properties of glass-ceramic material at a microwave frequency in X-band is measured. The variations of return loss and input impedance with frequency in $\mathrm{C} / \mathrm{X}$ bands and radiation characteristics of the proposed glass-ceramic antenna at the antenna resonant frequency obtained through measurement are reported. The experimental results for resonant frequency and return loss bandwidth of CDRA are also compared with corresponding theoretical values.

\section{Material Synthesis and Characterization}

2.1. Preparation of Glass-Ceramic Material Based on $\mathrm{B}_{2} \mathrm{O}_{3}-\mathrm{La}_{2} \mathrm{O}_{3}-\mathrm{MgO}$ Glass with $\mathrm{La}\left(\mathrm{Mg}_{0.5} \mathrm{Ti}_{0.5}\right) \mathrm{O}_{3}$ Ceramic. Microwave ceramic $\mathrm{La}\left(\mathrm{Mg}_{0.5} \mathrm{Ti}_{0.5}\right) \mathrm{O}_{3}$ (LMT) was prepared by the conventional mixed oxide method. High purity powders, $\mathrm{La}_{2} \mathrm{O}_{3}, \mathrm{MgO}$, and $\mathrm{TiO}_{2}$, with a molar ratio of nominal composition LMT were mixed and calcined at $1450^{\circ} \mathrm{C}$ for $4 \mathrm{~h}$. The glass $60 \mathrm{~B}_{2} \mathrm{O}_{3}-12 \mathrm{La}_{2} \mathrm{O}_{3}-28 \mathrm{MgO}$ (BLM) (in mol \%) was prepared by normal melting in a platinum crucible at $1200^{\circ} \mathrm{C}$ for $1 \mathrm{~h}$. Differential thermal analysis (DTA) was carried out for powdered glass specimens with NETZSCH STA429C analyzer at $10^{\circ} \mathrm{C} / \mathrm{min}$ heating rate. Contact angle between ceramic and glass was measured at different temperatures using DSA1 v 1.9-03, Kruss Gmbh, Hamburg. Sessile drop method was used for measuring contact angle. The sessile drop technique is a method used for the characterization of solid surface energies and, in some cases, aspects of liquid surface energies. The mixture of $50 \mathrm{wt}$ \% calcined ceramic

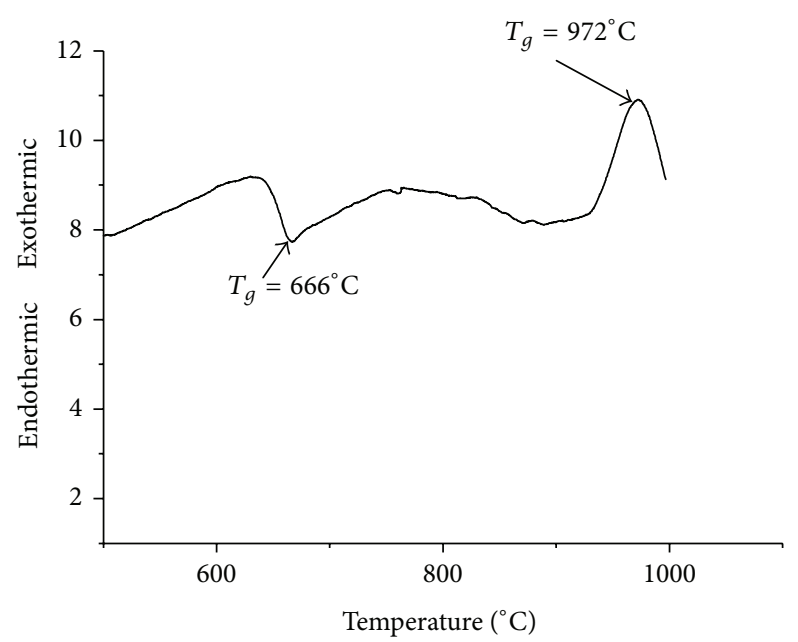

FIGURE 1: DTA pattern of glass (BLM).

LMT $\left(\mathrm{La}\left(\mathrm{Mg}_{0.5} \mathrm{Ti}_{0.5}\right) \mathrm{O}_{3}\right)$ with $50 \mathrm{wt} \%$ reactive glass BLM $\left(60 \mathrm{~B}_{2} \mathrm{O}_{3}-12 \mathrm{La}_{2} \mathrm{O}_{3}-28 \mathrm{MgO}\right)$ was first ball-milled for $24 \mathrm{~h}$. The milled powder was then dried at $120^{\circ} \mathrm{C}$ and granulated with PVA. Pellets were prepared by hydraulic press using cylindrical mold of $12.5 \mathrm{~mm}$ diameter at a pressure of $60 \mathrm{kN}$. The pellets of glass-ceramic were sintered at $850-950^{\circ} \mathrm{C}$ for $2 \mathrm{~h}$ in air with a heating rate of $5^{\circ} \mathrm{C} / \mathrm{min}$. The bulk densities of glass-ceramic pellets were measured from their dimension and mass. The sintered pellets were ground and powder $\mathrm{X}$-ray diffraction patterns were recorded using X-ray Diffractometer (Seifert) employing $\mathrm{Cu}-\mathrm{K} \alpha_{\mathrm{I}}$ radiation using an $\mathrm{Ni}$ filter to identify different crystalline phases present in the sintered samples. Microstructure observations of the natural surface of sintered glass-ceramic were studied by using Scanning Electron Microscope (JSM-840 LV, JEOL, Japan).

2.2. Differential Thermal Analysis (DTA). The differential thermal analysis (DTA) trace for BLM glass is shown in Figure 1. The convention for determining the glass transition temperature is to extend the straight-line portions of the baseline and the linear portion of the upward slope, marking their intersection. This shift in the base line shows a change in specific heat of the glass, which is attributed to the glass transition temperature $T_{g}$. The glass transition temperature has been found to be $666^{\circ} \mathrm{C}$. DTA pattern of glass samples shows one exothermic peak. It represents the temperature at which the rate of crystallization of different phases is maximum. Glass crystallization temperature has been found to be $972^{\circ} \mathrm{C}$.

2.3. Contact Angle. We took a small drop of glass (BLM) and placed it upon the sintered ceramic pellet (LMT). The pellet and the glass were inserted inside the instrument furnace. The temperature of the furnace was increased at the rate of $10^{\circ} \mathrm{C} / \mathrm{min}$. Shape of the glass droplet was recorded at some fixed interval of time. The recorded photographs are shown in Figures 2(a) and 2(b). From Figures 2(a) and $2(\mathrm{~b})$ it can be observed that at $800^{\circ} \mathrm{C}$ the glass drop 


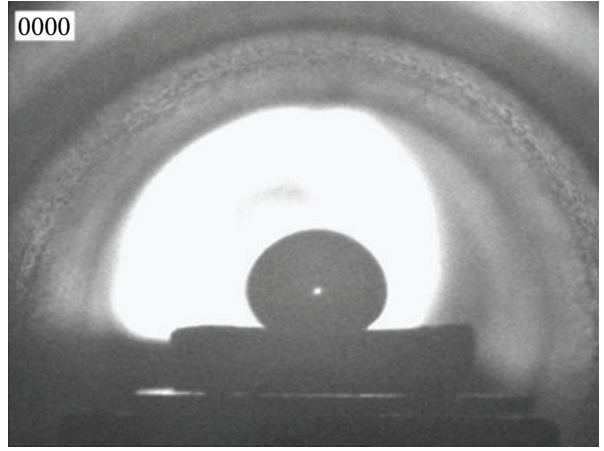

(a)

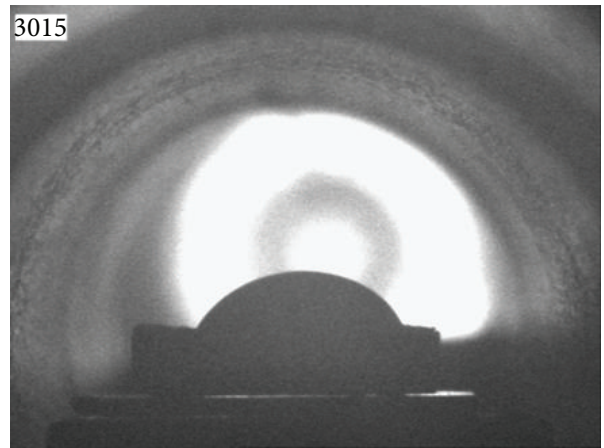

(b)

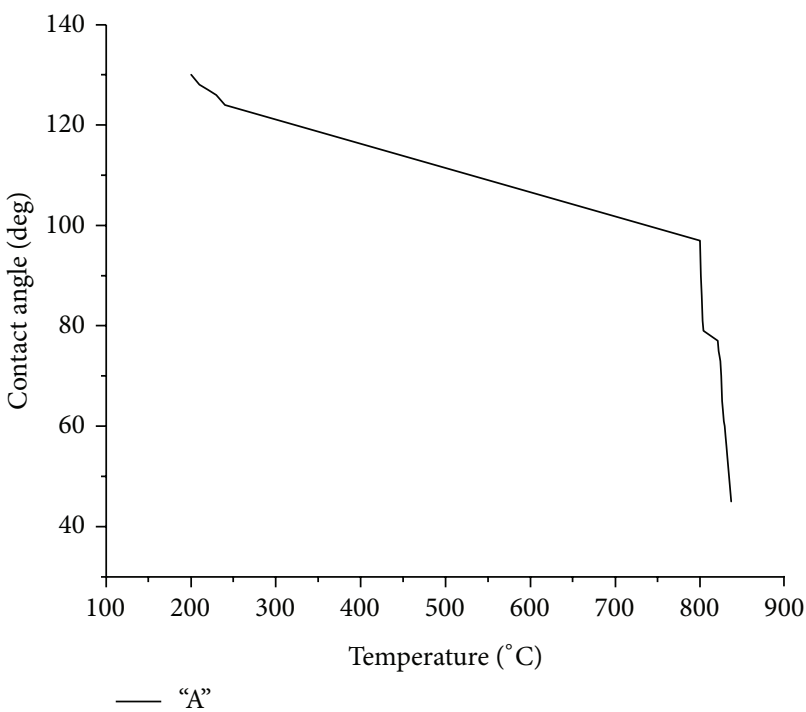

(c)

Figure 2: Contact angle variation with respect to temperature (a) at $200^{\circ} \mathrm{C}$, (b) at $850^{\circ} \mathrm{C},(\mathrm{c})$ from $200^{\circ} \mathrm{C}$ to $850^{\circ} \mathrm{C}$.

became softer and the contact angle reduces. At $850^{\circ} \mathrm{C}$ glass drop reaches the condition of melting. Figure 2(c) shows the variation of contact angle with temperature for glass. It is clear from Figure 2 (c) that $850^{\circ} \mathrm{C}$ is the minimum temperature for sintering the LTCC glass-ceramic sample. In this way glass material lowers the sintering temperature of microwave glass-ceramic and makes it LTCC glass-ceramic.

2.4. Density Measurement. The density of glass-ceramic as a function of sintering temperature is shown in Figure 3. Densities of the pressed pellets were measured from the dimensions and weight of the samples.

The measured density was $2.546 \mathrm{gm} / \mathrm{cc}$. With the increase of sintering temperature, density of glass-ceramic decreased. The reaction between BLM glass and LMT ceramic was enhanced with sintering temperature, which is evident from XRD analysis.

2.5. X-Ray Diffraction. X-ray diffraction (XRD) patterns for LTCC glass-ceramic samples (LMT-BLM) sintered at 850,
900 , and $950^{\circ} \mathrm{C}$ for $4 \mathrm{hr}$ are shown in Figure 4. All the peaks in XRD patterns were matched with JCPDS files of various compound oxides of the constituent elements. LTCC sample sintered at $850^{\circ} \mathrm{C}$ contains ceramic phases LMT and $\mathrm{LaBO}_{3}$. With increasing sintering temperature LMT phase disappears, and $\mathrm{LaBO}_{3}$ and $\mathrm{TiO}_{2}$ form as reported by Lin et al. [16].

2.6. Fourier Transform Spectroscopy. The infrared (IR) spectra for the glass-ceramic sample are shown in Figure 5. The IR spectra of these glass-ceramics generally consist of broad and sharp bands in different regions (500 to $5000 \mathrm{~cm}^{-1}$ ). IR spectra of each sample show a number of absorption bands. The IR absorption spectra of these samples show two peaks for glass-ceramic sample. The peaks are sharp and broad in nature. All the absorption peaks are numbered 1 and 2 starting from low wave number side. In Figure 5 the first absorption peak (1) lies between 492 and $750 \mathrm{~cm}^{-1}$. This observed broad peak is due to stretching of $\mathrm{BO}_{3}{ }^{-}$bond inside the glassy network. The second absorption peak (2) lies at $1280 \mathrm{~cm}^{-1}$. It is due to $\mathrm{TiO}_{4}{ }^{-}$bond. 


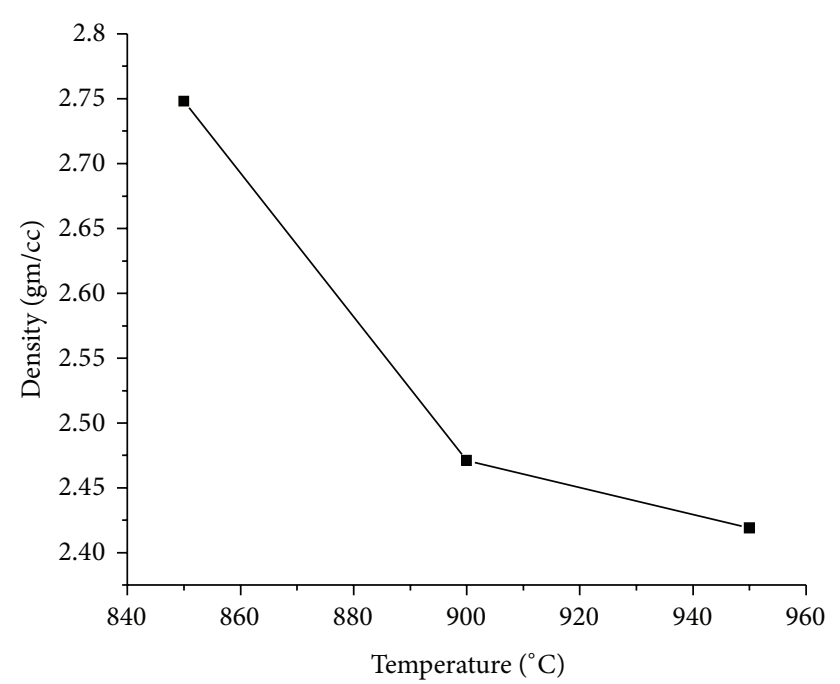

FIgURE 3: Variation of density with temperature.

2.7. Measurement of Dielectric Constant of Glass-Ceramic Material. Microwave dielectric properties of glass-ceramic materials in the frequency range of $2-10 \mathrm{GHz}$ were measured using a vector network analyzer (Agilent 8722ES). The $\varepsilon_{r}$ was obtained from the $\mathrm{TE}_{011}$ resonance mode of the endshorted sample placed between two conducting plates, using the method of Hakki and Coleman [17] and modified by Courtney (Figure 6(a)). The reflection method was used for measuring the Q-factor, in which the sample was placed at the center of a cylindrical resonant cavity having dimensions three times greater than the sample dimensions (Figure 6(b)). The measurement was done with the $\mathrm{TE}_{011}$ mode considering weakly-coupled case and the correction for the coupling coefficient was applied [18]. The obtained dielectric constant and loss tangent of the glass-ceramic material are 7.735 and 0.00422 , respectively, at $8 \mathrm{GHz}$.

\section{Antenna Configuration, Theoretical Expressions for Resonant Frequency, Q-Factor, and Return Loss Bandwidth}

The dual segment CDRA consists of lower segment made from Teflon sheet with dielectric constant $\varepsilon_{r 1}=2.08$ and an upper segment of glass-ceramic $\left(\mathrm{B}_{2} \mathrm{O}_{3}-\mathrm{La}_{2} \mathrm{O}_{3}-\mathrm{MgO}\right.$ glass with $\mathrm{La}\left(\mathrm{Mg}_{0.5} \mathrm{Ti}_{0.5}\right) \mathrm{O}_{3}$ ceramic) block with $\varepsilon_{r 2}=7.735$ as shown in Figure 7. The dual segment CDRA is placed on a ground plane of size $60 \times 60 \times 4 \mathrm{~mm}^{3}$. The lower and upper segments of the CDRA have dimensions of $D \times l=14.15 \times$ $10 \mathrm{~mm}^{2}$ and $D \times l_{1}=14.15 \times 6 \mathrm{~mm}^{2}$, respectively. The CDRA is assumed to be excited by a $50 \Omega$ coaxial probe of outer radius $2 \mathrm{~mm}$ and inner radius $0.6 \mathrm{~mm}$. The probe height above the surface of ground plane is found by trial and error to be $9.5 \mathrm{~mm}$ to provide lowest return loss at resonant frequency.

The resonant frequency of single segment CDRA excited in $\mathrm{HEM}_{11 \delta}$ mode can be written as, $[1,19]$,

$$
f=\frac{6.324 c}{2 \pi a \sqrt{2+\varepsilon_{r}}}\left\{0.27+0.36 \frac{a}{2 h}+0.02\left(\frac{a}{2 h}\right)^{2}\right\},
$$


FIGURE 4: X-ray diffraction pattern of glass-ceramic.

where $a=D / 2, D$ is the diameter of CDRA, $h$ is the height of the CDRA above ground plane, $c$ is the velocity of microwave in free space $\left(=3 \times 10^{8} \mathrm{~m} / \mathrm{sec}\right)$, and $\varepsilon_{r}$ is the relative permittivity of CDRA material.

Equation (1) has been obtained through curve fitting and numerical simulations based on the method of moments [1, 20].

Radiation Q-factor of isolated CDRA can be written as, $[1,19]$,

$Q=0.01007\left(\varepsilon_{r}\right)^{1.3}\left(\frac{a}{h}\right)\left[1+100 e^{-\left[2.05(a / 2 h)-\left(1 / 80(a / h)^{2}\right)\right]}\right]$. 

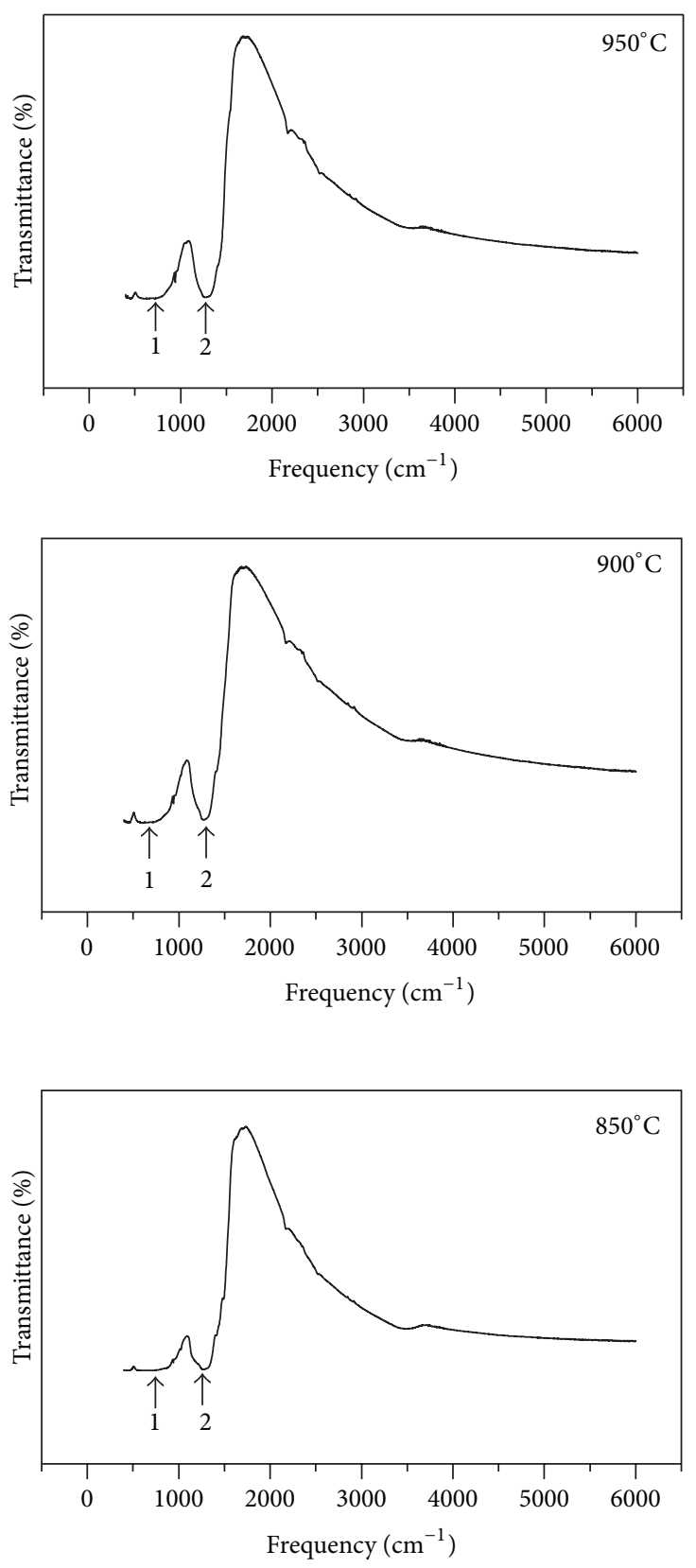

FIGURE 5: Infrared spectra of glass-ceramic sample.

The percentage bandwidth of the isolated CDRA is given by, $[1,19]$,

$$
\% B W=\frac{S-1}{\sqrt{S Q}} \times 100
$$

where $S$ and $Q$ are the VSWR and the radiation $Q$-factor of isolated CDRA.

Equations (1)-(3) can be used to compute the resonant frequency, radiation $Q$-factor, and bandwidth of the dual segment CDRA by replacing CDRA material dielectric constants $\varepsilon_{r}$ and $h$ and $\varepsilon_{\text {eff }}$ with $h_{\text {eff }}$, respectively. Adopting a simple static capacitance model, the following expressions for effective permittivity $\left(\varepsilon_{\text {eff }}\right)$ and effective height $\left(h_{\text {eff }}\right)$ are obtained:

$$
\begin{gathered}
\varepsilon_{\mathrm{eff}}=\frac{h_{\mathrm{eff}}}{\left(1 / \varepsilon_{r 1}\right)+\left(1 / \varepsilon_{r 2}\right)}, \\
h_{\mathrm{eff}}=l+l_{1} .
\end{gathered}
$$

See [6], where $l$ and $l_{1}$ are the length of lower and upper segments of CDRA, respectively.

The resonant frequency, $Q$-factor, and bandwidth of the dual segment CDRA computed using (1), (2), and (3) are found to be $6.225 \mathrm{GHz}, 1.6644$, and $42.4842 \%$, respectively.

\section{Experimental Results and Discussion}

4.1. Variations of Return Loss and Input Impedance versus Frequency. Measurement of return loss and input impedance of dual segment CDRA as a function of frequency in C/X bands was done using Agilent PNA series vector network analyzer (model number E8364 B). The measured variations of return loss and input impedance with frequency for the CDRA are shown in Figures 8 and 9, respectively. From Figure 8 the resonant frequency, operating frequency range, and the percentage bandwidth of the proposed CDRA are extracted. The resonant frequency, operating frequency range, and the percentage bandwidth of the CDRA in presence of coaxial feed are found to be $6.31 \mathrm{GHz}, 6.01-7.69 \mathrm{GHz}$, and $26.62 \%$, respectively.

The measured resonant frequency of the antenna is nearly in agreement with the theoretical value of $6.225 \mathrm{GHz}$. The measured bandwidth of the antenna is lower than the theoretical value. The deviation in the results may be due to fabrication tolerances, the possibility of misalignment in the placement of two DRA segments, the effect of finite ground plane not considered in theoretical computation, and the effect of glue used to bind the two DRA segments during fabrication of antenna. In fact using LTCC material in combination with Teflon reduces the effective dielectric constant of the antenna structure as a whole, thereby reducing the radiation $Q$-factor of DRA which enhances the bandwidth of the antenna. Some other ceramic materials have been used earlier to design probe fed multisegment DRA/DRAs with air gap in which wide bandwidth has been obtained with the help of lower dielectric constant inserts [21-23].

The input resistance at resonant frequency of the CDRA is found to be $50.3 \Omega$ (Figure 9) providing very good impedance match to $50 \Omega$ coaxial feeder. It is also worth noting from Figure 9 that the frequency at which input resistance becomes maximum is slightly lower than that at which input reactance becomes zero. This can be due to the effect of coaxial feed inductance.

4.2. Far Field Performance. The copolar and cross-polar radiation patterns of the CDRA for $\Phi=0^{\circ}$ plane ( $x-z$ plane) and $\Phi=90^{\circ}$ plane $(y-z$ plane $)$ were measured in anechoic chamber at the measured resonant frequency of $6.31 \mathrm{GHz}$. The experimental setup is not shown here for brevity. The measured E- and $\mathrm{H}$-plane patterns of the CDRA are shown in Figures 10 and 11, respectively. 


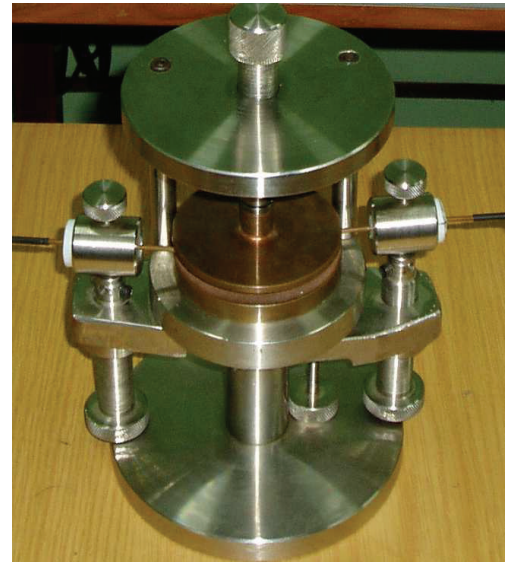

(a)

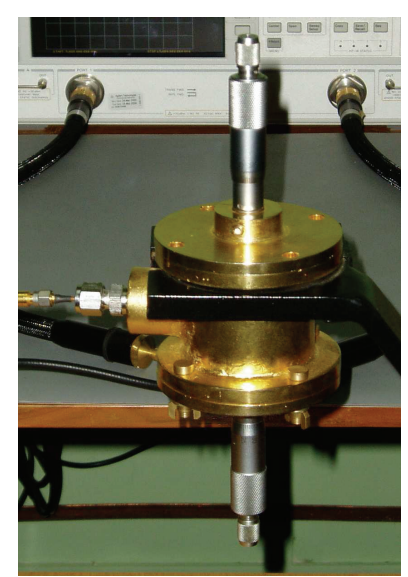

(b)

Figure 6: Setup for (a) $\varepsilon_{r}$ measurement and (b) Q-factor measurement.

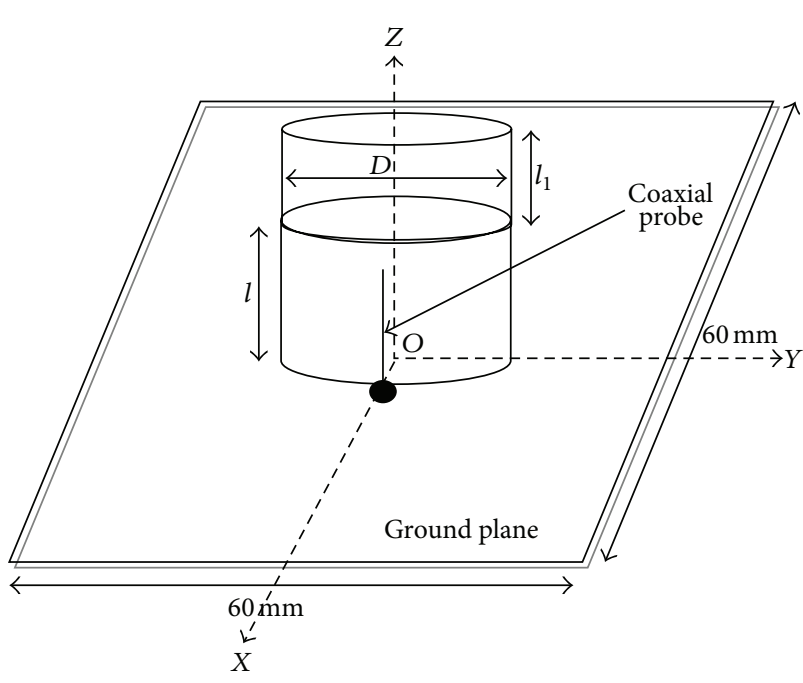

FIGURE 7: Geometry of dual segment CDRA.

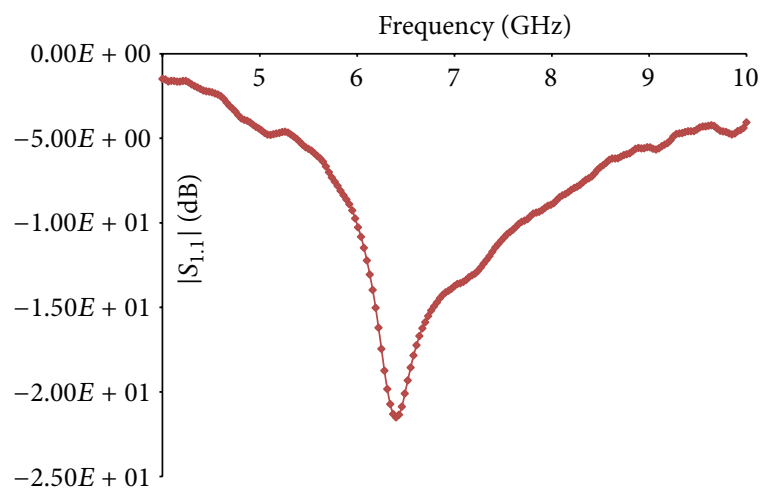

FIGURE 8: Variation of return loss versus frequency of dual segment cylindrical DRAs fabricated from glass-ceramic material.

The half power beam width (HPBW), first side lobe level and maximum cross-polarized lobe level, of the CDRA are extracted from Figures 10 and 11. The HPBWs of the antenna in E- and H-planes are found to be $51.2^{\circ}$ and $59.2^{\circ}$,

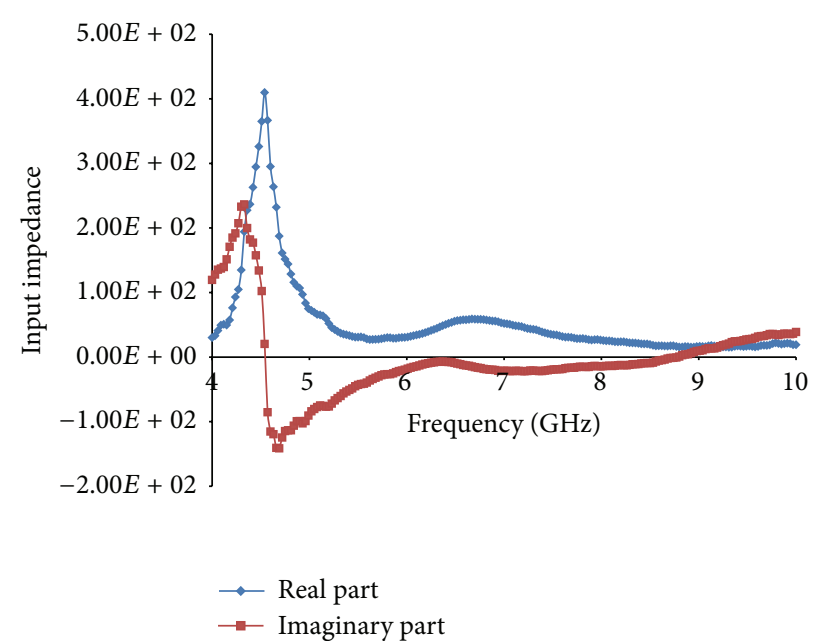

FIGURE 9: Variation of input impedance with frequency for dual segment CDRA fabricated from glass-ceramic material.

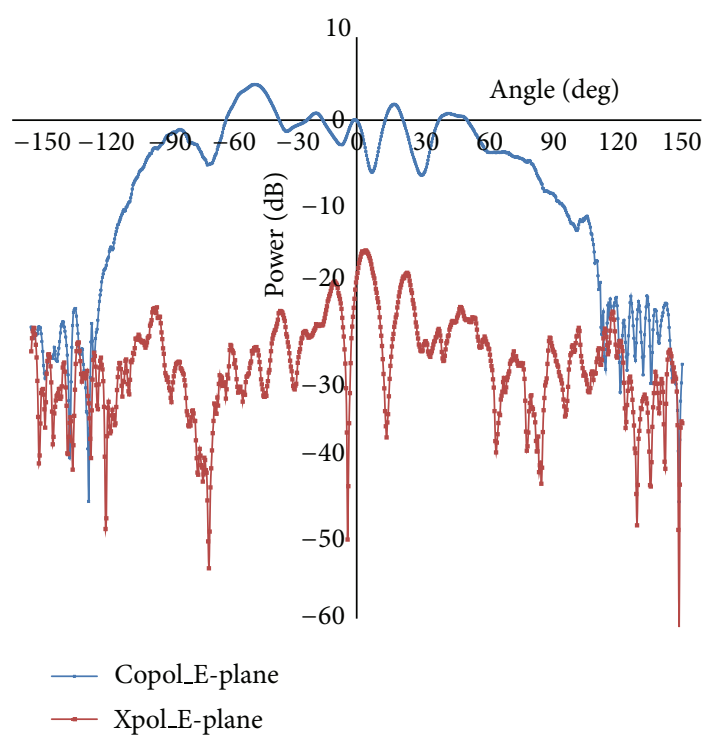

FIGURE 10: E-plane radiation pattern of dual segment CDRA. 


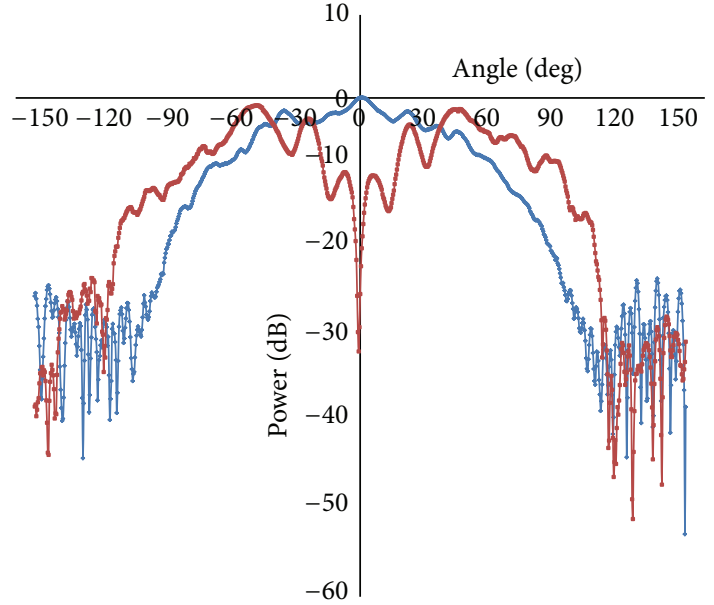

$\rightarrow$ Copol_H-plane

$\rightarrow$ Xpol_H-plane

FIGURE 11: H-plane radiation pattern of dual segment CDRA.

respectively. The first side lobe levels of CDRA in E- and $\mathrm{H}$ planes are $1.904 \mathrm{~dB}$ and $-1.629 \mathrm{~dB}$ loose, respectively, whereas cross-polarized lobe levels of the antenna in these planes are found to be $-15.72 \mathrm{~dB}$ and $-1.335 \mathrm{~dB}$, respectively. Asymmetry in E-plane copolarization pattern can be seen in Figure 10. This may be due to the use of antenna material having very low effective dielectric constant value, which degrades the radiation pattern of the antenna [6]. But at the same time performance improvement of antenna in terms of bandwidth is also obtained due to reduction in its quality factor. Higher cross-polarized lobe level in H-plane $\left(\Phi=0^{\circ}\right)$ is obtained due to significant height (above ground plane) of coaxial probe coupling energy into the antenna which may result in spurious radiation.

The measured gain of the CDRA is found to be $2.18 \mathrm{~dB}$ at the resonant frequency of $6.31 \mathrm{GHz}$.

\section{Conclusion}

An experimental study on wideband dual segment CDRA fabricated from glass-ceramic material, which is based on $\left(\mathrm{B}_{2} \mathrm{O}_{3}-\mathrm{La}_{2} \mathrm{O}_{3}-\mathrm{MgCO}_{3}\right)$ glass and $\mathrm{La}\left(\mathrm{Mg}_{0.5} \mathrm{Ti}_{0.5}\right) \mathrm{O}_{3}$ ceramic, along with its material characteristics has been carried out. Low temperature cofired glass-ceramic material based on $\left(\mathrm{B}_{2} \mathrm{O}_{3}-\mathrm{La}_{2} \mathrm{O}_{3}-\mathrm{MgCO}_{3}\right)$ glass and $\mathrm{La}\left(\mathrm{Mg}_{0.5} \mathrm{Ti}_{0.5}\right) \mathrm{O}_{3}$ ceramic were fabricated at sintering temperatures of less than $1000^{\circ} \mathrm{C}$. From DTA and contact angle studies the minimum sintering temperature for LTCC glass-ceramic material through Liquid-phase sintering procedure is found to be $850^{\circ} \mathrm{C}$. With increase in temperature, density of material increases. From the experimental study on proposed dual segment CDRA it is inferred that the proposed antenna provides wide bandwidth and reasonable gain though at the cost of degradation in radiation pattern.
From these results it is concluded that LTCC dielectric resonator antenna may find potential application in wireless communication field for designing a multisegment wideband antenna through proper selection and optimization of segment materials and material composition.

\section{References}

[1] R. K. Mongia and P. Bhartia, "Dielectric resonator antennas: a review and general design relations for resonant frequency and bandwidth," International Journal of Microwave and MillimeterWave Computer-Aided Engineering, vol. 4, no. 3, pp. 230-247, 1994.

[2] R. K. Mongia and A. Ittipiboon, "Theoretical and experimental investigations on rectangular dielectric resonator antennas," IEEE Transactions on Antennas and Propagation, vol. 45, no. 9, pp. 1348-1356, 1997.

[3] P. Rezaei, M. Hakkak, and K. Forooraghi, "Design of wide-band dielectric resonator antenna with a two-segment structure," Progress in Electromagnetics Research, vol. 66, pp. 111-124, 2006.

[4] D. Kajfez and A. A. Kishk, "Dielectric resonator antennapossible candidate for adaptive antenna arrays," in Proceedings of the VITEL, International Symposium on Telecommunications, Next Generation Networks and Beyond, Portoroz, Slovenia, May 2002.

[5] M. Saed and R. Yadla, "Microstrip-fed low profile and compact dielectric resonator antennas," Progress in Electromagnetics Research, vol. 56, pp. 151-162, 2006.

[6] A. Petosa, Dielectric Resonator Antennas Handbook, Artech House, London, UK, 2007.

[7] Y. Ge and K. P. Esselle, "A dielectric resonator antenna for UWB applications," in Proceedings of the IEEE International Symposium on Antennas and Propagation and USNC/URSI National Radio Science Meeting (APSURSI '09), Charleston, SC, USA, June 2009.

[8] D. W. Kim, D. G. Lee, and K. S. Hong, "Low-temperature firing and microwave dielectric properties of $\mathrm{BaTi}_{4} \mathrm{O}_{9}$ with $\mathrm{Zn}-\mathrm{B}-\mathrm{O}$ glass system," Materials Research Bulletin, vol. 36, no. 3-4, pp. 585-595, 2001.

[9] T. Mailadil Sebastian, "Dielectric materials for wireless communication," in Low Temperature Cofired Ceramics, Chapter 12, pp. 445-511, Elsevier publication, 2008.

[10] C. C. Cheng, T. E. Hsieh, and I. N. Lin, "The effect of composition on Ba-Nd-Sm-Ti-O microwave dielectric materials for LTCC application," Journal of European Ceramic Society, vol. 79, no. 2-3, pp. 119-123, 2003.

[11] J. M. Wu and H. L. Huang, "Microwave properties of zinc, barium and lead borosilicate glasses," Journal of Non-Crystalline Solids, vol. 260, no. 1-2, pp. 116-124, 1999.

[12] M. Valant and D. Suvorov, "Microstructural phenomena in lowfiring ceramics," Materials Chemistry and Physics, vol. 79, no. 23, pp. 104-110, 2003.

[13] R. R. Tummala, "Ceramic and glass-ceramic packaging in the 1990s," Journal of American Ceramic Society, vol. 74, no. 5, pp. 895-908, 1991.

[14] D.-Y. Lee, S.-J. Yoon, J. H. Yeo et al., "Crystal structure and microwave dielectric properties of $\mathrm{La}\left(\mathrm{Mg}_{1 / 2} \mathrm{Ti}_{1 / 2}\right) \mathrm{O}_{3}$ ceramics," Journal of Materials Science Letters, vol. 19, no. 2, pp. 131-134, 2000.

[15] M. P. Seabra and V. M. Ferreira, "Synthesis of $\mathrm{La}\left(\mathrm{Mg}_{0.5} \mathrm{Ti}_{0.5}\right) \mathrm{O}_{3}$ ceramics for microwave applications," Materials Research Bulletin, vol. 37, no. 2, pp. 255-262, 2002. 
[16] H. Lin, L. Luo, and W. Chen, "Microwave dielectric properties of low temperature co-fired glass-ceramic based on $\mathrm{B}_{2} \mathrm{O}_{3}-\mathrm{La}_{2} \mathrm{O}_{3}$ $\mathrm{MgO}$ glass with $\mathrm{La}\left(\mathrm{Mg}_{0.5} \mathrm{Ti}_{0.5}\right) \mathrm{O}_{3}$ ceramics," Materials Letters, vol. 62, no. 4-5, pp. 611-614, 2008.

[17] B. W. Hakki and P. D. Coleman, "A dielectric resonator method of measuring inductive capacities in the millimeter range," IEEE Transactions on Microwave Theory and Techniques, vol. 8, no. 4, pp. 402-410, 1960.

[18] D. Kajfez and E. J. Hwan, "Q-factor measurement with network analyzer," IEEE Transactions on Microwave Theory and Techniques, vol. 32, no. 7, pp. 666-670, 1984.

[19] A. A. Kishk, A. W. Glisson, and G. P. Junker, "Study of broadband dielectric resonator antennas," in Proceedings of the Antenna Application Symposium, pp. 45-68, 1999.

[20] A. A. Kishk, A. W. Glisson, and D. Kajfez, "Computed resonant frequency and far fields of isolated disks," in Proceedings of the IEEE Antennas and Propagation International Symposium, pp. 408-411, Ann Arbor, Mich, USA, 1993.

[21] M. Cooper, A. Petosa, A. Ittipiboon, and J. S. Wight, "Investigation of dielectric resonator antennas for L-band communications," in Antenna Technology and Applied Electromagnetics Symposium (ANTEM '96), pp. 167-170, Ottawa, Canada, August 1996.

[22] G. P. Junker, A. A. Kishk, A. W. Glisson, and D. Kajfez, "Effect of fabrication imperfections for ground-plane-backed dielectricresonator antennas," IEEE Antennas and Propagation Magazine, vol. 37, no. 1, pp. 40-47, 1995.

[23] M. Cooper, Investigation of current and novel rectangular dielectric resonator antennas for broadband applications at L-Band [M.S. thesis], Carleton University, 1997. 

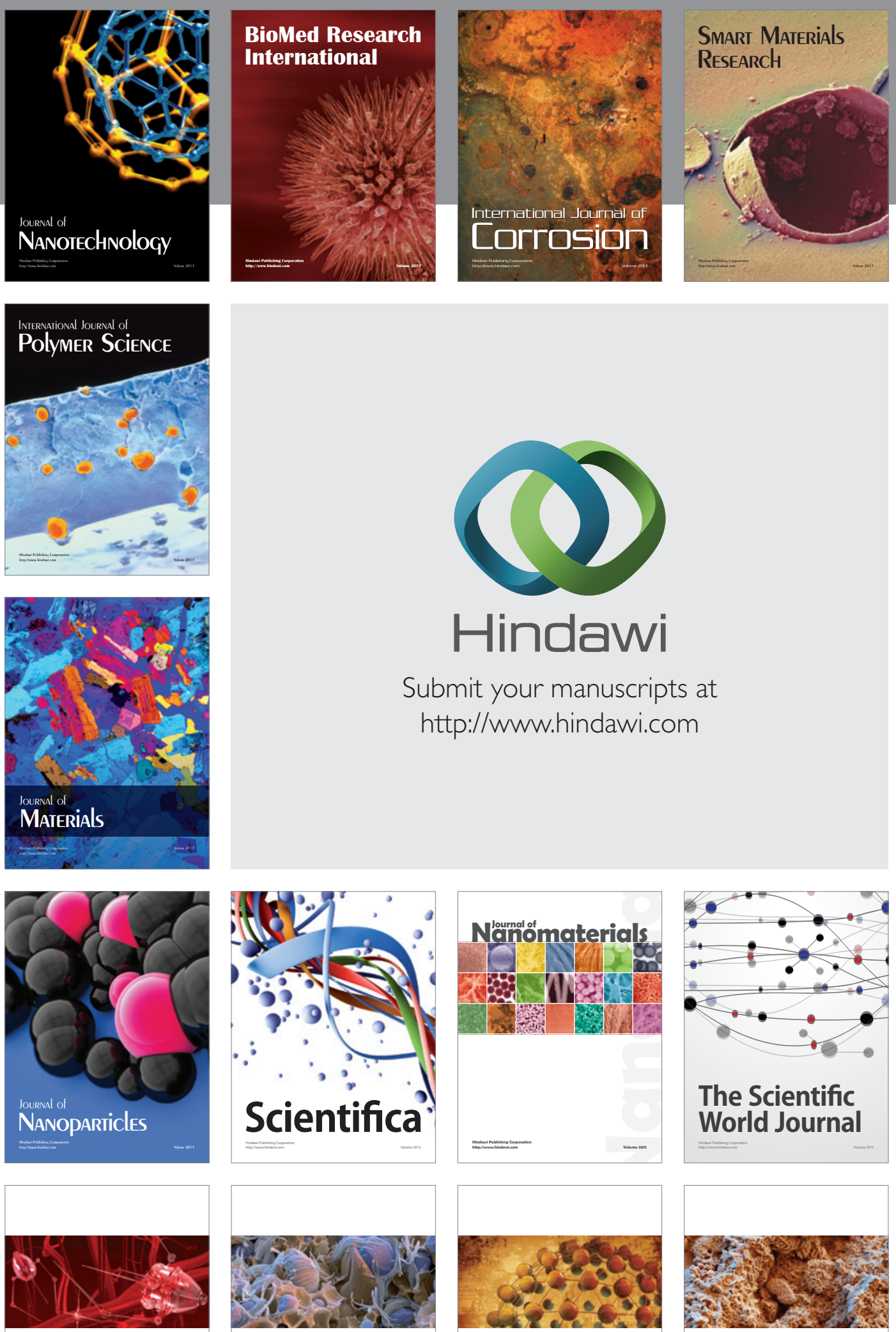

ISRN

Nanotechnology
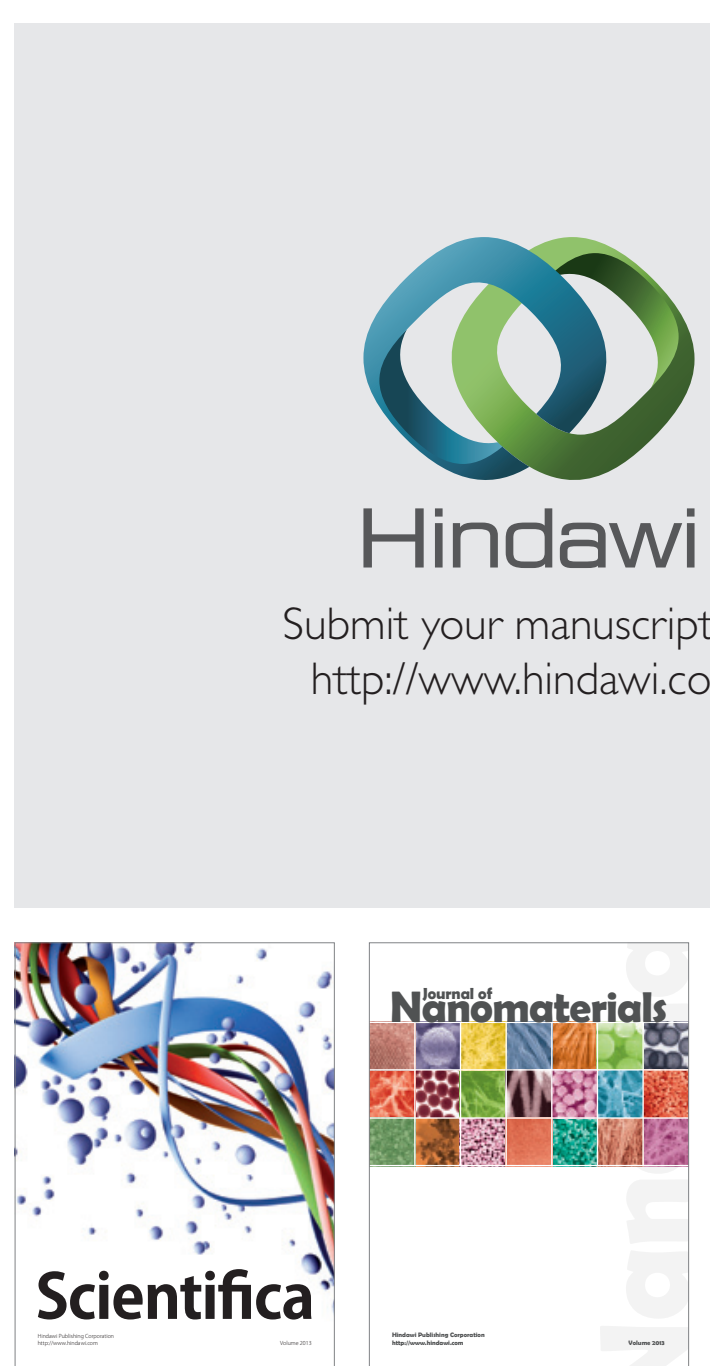

Submit your manuscripts at http://www.hindawi.com
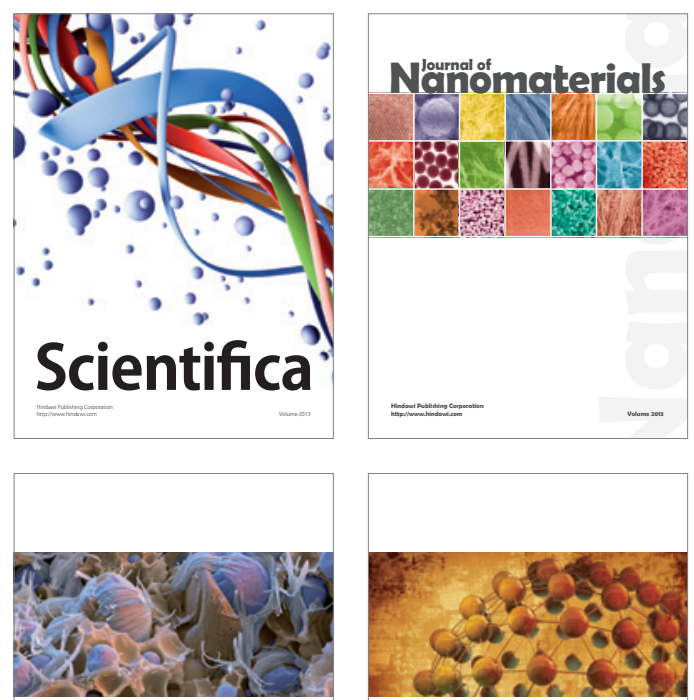

ISRN

Polymer Science

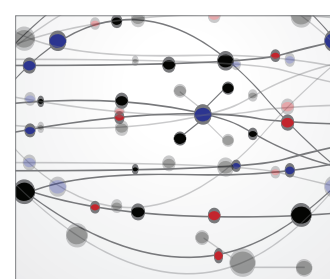

The Scientific World Journal

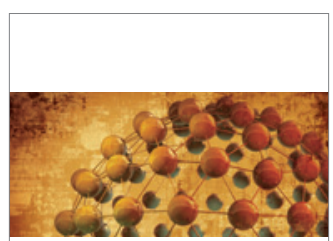

ISRN

Materials Science

\section{World Jounal}

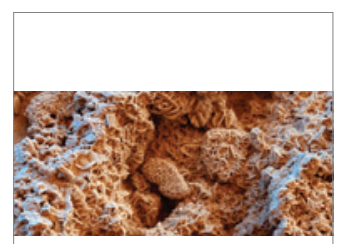

ISRN

Corrosion
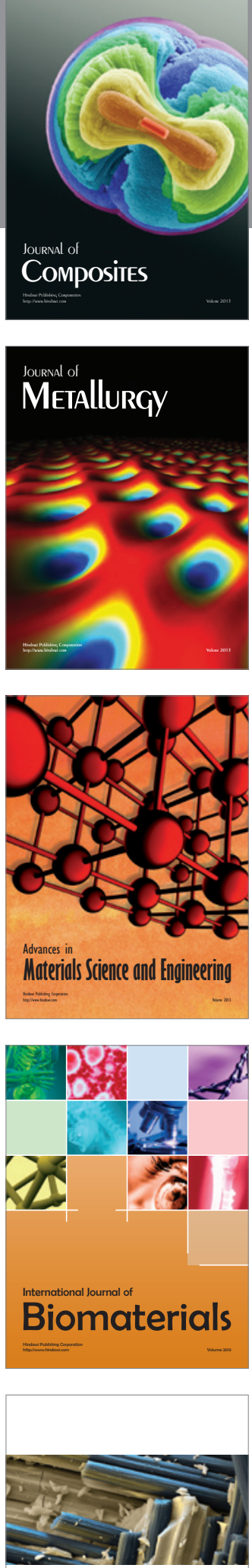

ISRN

Ceramics 